\title{
Pendidikan dalam Keluarga Berbasis Etika Buddha
}

\author{
Sapardi \\ Sekolah Tinggi Agama Buddha Negeri Sriwijaya Tangerang, Indonesia \\ Sapardi65@gmail.com
}

\begin{abstract}
This study aims to find out familial education on the basis of Buddhist ethics and the relationship of Buddhist teachings in building a happy, prosperous family life. The foregoing rests upon the identification of texts from the Tipitaka / Tripitaka Scriptures related to Education in the Family and moral ethics (Sila), and the texts are subsequently analyzed and dissected using the theory of structural functionalism and hermeneutics. Based on the analysis of the aforesaid text data, it can be seen the role of moral ethics that must be put forward and become a guide in shaping a happy and prosperous family life. Education in the Family is a pattern or method that must be done by a Buddhist household. Based on ethics in managing hittasukkhaya life, it becomes the basis and guide in creating happy and prosperous home life (hitta sukkhaya). Moral ethics (Sila) is the basis and foundation and guide for householders in creating a happy and prosperous life in the face of various changes that occur in the current modern era.
\end{abstract}

Keywords: Family Education, Buddhist ethics.

\begin{abstract}
Abstrak
Penelitian ini bertujuan untuk mengetahui Pendidikan Dalam Keluarga Berbasis Etika Buddha, serta keterkaitan tema-tema ajaran Buddha dalam membangun kehidupan keluarga bahagia sejabtera. Berdasarkan identifikasi teks-teks dari Kitab Suci Tipitaka/Tripitaka yang terkait dengan Pendidikan Dalam Keluarga dan etika moral (Sila) dan selanjutnya dianalisis serta dibedah dengan menggunakan teori fungsionalisme structural dan hermeneutik. Berdasarkan analisis data teks dimaksud, dapat diketabui peran etika moral yang harus dikedepankan dan menjadi panduan dalam membentuk kebidupan keluarga bahagia dan sejabtera. Pendidikan Dalam Keluarga adalah sebuah pola atau cara yang harus dilakukan para perumab tangga seorang Buddhis. Dengan berbasis etika dalam mengatur kehidupan hittasukkhaya, menjadi dasar dan panduan dalam menciptakan kebidupan rumah tangga yang bahagia dan sejabtera (hitta sukkhaya). Etika moral (Sila) menjadi dasar dan fondasi serta panduan bagi para perumah tangga dalam menciptakan kebidupan bahagia dan sejabtera dalam menghadapi berbagai perubahan yang terjadi pada era modern sekarang ini.
\end{abstract}

Kata Kunci: Pendidikan Dalam Keluarga, etika Buddha.

Permalink/DOI: https://doi.org/10.18326/infsl3.v14i1.141-158 


\section{Pendahuluan}

Dalam menyongsong masa depan anak-anak, bahwa kesuksesan maupun kegagalan anak-anak sangat dipengaruhi oleh peran orangtua. Pendidikan pada masa kecil dari orang tua kepada anak akan memberikan dasar terpenting dalam perkembangan anak. Hal ini yang sering dilupakan oleh orangtua. Terkadang orangtua cenderung menganggap anaknya tidak atau belum tahu apa-apa. Orangtua merasa tidak perlu memberikan kesempatan untuk mengkomunikasikan pikirannya kepada anak-anaknya. Mereka menganggap anak-anaknya belum saatnya berbicara dan berdiskusi tentang sesuatu masalah dalam keluarga. Sikap ini tentu akan menjadi satu penghambat hubungan komunikasi antara orangtua dengan anak. Sebagaimana Buddha ajarkan kepada siswa-Nya dalam Sigalovada Sutta bahwa orangtua memiliki kewajiban dan peran yang sangat panting dalam membina dan mengarahkan pendidikan dalam keluarga. Sejak lahir hingga besar, anak-anak tinggal bersama orangtua dan orangtua yang mempunyai kewajiban untuk memberikan yang baik kepada anak-anaknya, baik pendidikan formal maupun informal. Dalam upaya membangun keluarga yang bahagia dan harmonis ( hittasukkhaya), perlu adanya tatanan moral yang harus diupayakan dan dilaksanakan dalam keluarga oleh seluruh anggota keluarga. Oleh karena itu, perlu adanya pengetahuan dan pemahaman yang benar terkait dengan proses pendidikan yang semestinya diterapkan.

Pada zaman modern sekarang ini, kehidupan manusia dipenuhi dengan berbagai macam ketegangan dan tekanan. Kerap kali ketegangan dan tekanan inilah yang menimbulkan banyak masalah dalam kehidupan keluarga. Terjadinya ketegangan tersebut terutama bersumber dari keegoisan dan kurangnya kesabaran, toleransi dan pengertian bersama. Dalam Sigalovada Sutta Sang Buddha memberikan nasehat baik tentang bagaimana menjaga kedamaian dan keharmonisan di dalam kehidupan berumah tangga. Masing-masing anggota keluarga memeiliki tanggungjawab, seperti tanggung jawab orangtua terhadap anak-anaknya dan kewajiban anak terhadap orangtuanya.

Peran agama menjadi yang sangat penting dalam kehidupan keluarga, karena keluarga yang agamis dan menjalani ritual 
keagamaan secara rutin akan sangat membantu mereka dalam mengatasi masalah-masalah hidup dan kehidupan. Dalam menciptakan kondisi keluarga yang harmonis, perlu adanya upayaupaya yang berkesinambungan dari semua anggota keluarga. Upaya mewujudkan pendidikan dalam keluarga Berbasis Etika Buddha pada era globalisasi saat ini, menjadi tuntutan yang sangat penting bagi perumah tangga. Etika menjadi standar moral bagi seluruh anggota keluarga dalam berperilaku.

Pada era modern yang ditandai dengan adanya kemajuan ilmu pengetahuan dan teknologi, membuat perubahan dan memberikan dampak serius dalam kehidupan masyarakat. Perubahan-perubahan perilaku manusia pada zaman modern sekarang ini menjadi tantangan tersendiri bagi keluarga dalam kehidupan bermasyarakat, mengingat banyak perilaku atau tindakan yang merugikan diri sendiri atau pun juga keluarga. Oleh karena itu, diperlukan adanya etika yang menjadi panduan dan pedoman dalam kehidupan keluarga dan etika/moral ajaran Buddha menjadi pedoman perilaku keseharian. Dalam keluarga Buddhis bahwa permasalahan-permasalahan yang terjadi tidak bedanya dengan keluarga umat beragama lainnya. Permasalahan adalah bagaimana membangun keluarga yang harmonis dan sejahtera. Pentingnya pendidikan yang kuat sebagai dasar dalam membangun jiwa manusia. Melalui pendidikan yang benar, etika dapat disampaikan dengan baik.

Dalam kehidupan masyarakat, termasuk dalam kehidupan keluarga sekarang ini banyak terjadi perilaku amoral yang luar biasa. Perilaku-perilaku kejahatan di masyarakat, seperti terjadinya pembunuhan, penipuan, korupsi, pelecehan, perampokan, dll. Berdasarkan berbagai permasalahan tersebut, hal ini sangat terkait dengan masalah etika dan masalah ekonomi yang terjadi di masyarakat saat ini. Penataan kehidupan keluarga untuk bisa hidup sejahtera (bita sukkhaya) menjadi hal yang penting dimulai dengan pemenuhan sektor ekonomi. Dalam usaha menciptakan hal tersebut tidak terlepas dari pola pendidikan yang dibangun dalam kehidupan hittasukkhaya. Pendidikan dalam hubungannya dengan kehidupan bittasukkhaya dalam hal ini adalah sebuah proses yang khas dari berbagai perencanaan, tindakan, pengorganisasian termasuk pengawasan dalam kehidupan keluarga yang berdasar 
pada ajaran Buddha. Semua itu untuk mencapai target tertentu dan sasaran yang diinginkan dengan memanfaatkan sumber daya yang ada, termasuk sumberdaya pikiran sebagai pengendali utama.

Dalam penelitian ini penting untuk mengetahui pendidikan dalam keluarga berbasis etika dalam kehidupan perumah tangga. Ada kekhawatirkan jika pendidikan yang benar dalam kehidupan hittasukkhaya khususnya bagi masyarakat Buddha tidak dipahami dan diterapkan dengan baik dan benar, maka kondisi terutama dalam kehidupan keluarga akan terjadi ketidakharmonisan. Hal ini didasarkan pada sikap individu yang memiliki dasar keserakahan (Lobha), kebencian (dosa) dan kebodohan (moha). Diyakini bahwa etika menurut ajaran Buddha berkaitan erat dengan pola pendidikan dalam penataan kehidupan hittasukkhaya. Oleh karena itu, bahwa pendidikan yang tepat dalam kehidupan hittasukkhaya akan dapat memberikan manfaat besar. Peneliti memiliki dugaan awal kehancuran tatanan dalam kehidupan keluarga tidak terlepas dari keserakahan, kebencian dan kebodohan manusia itu sendiri. Oleh karena itu, peneliti ingin mengungkapkan kembali pendidikan dalam keluarga berbasis etika Buddha. Dalam penelitian ini dapat dirumuskan pertanyaan sebagai berikut; (1) Mengapa Pendidikan Dalam Keluarga berbasis etika Buddha? (2) Bagaimana pendidikan dalam keluarga berbasis etika Buddha? 3) Apa manfaat pendidikan dalam keluarga berbasis etika Buddha?

Berdasarkan rumusan masalah, penelitian ini memiliki dua tujuan. Pertama, tujuan umum adalah untuk mengetahui pentingnya pendidikan dalam keluarga berbasis etika Buddha. Ini berarti pendidikan dan nilai-nilai etika Buddha dan manfaatnya dalam kehidupan hittasukkhaya. Peneliti dapat menyumbangkan ide-ide kepada umat Buddha, serta, sumber referensi atau landasan dalam menjalani masyarakat, bangsa, dan negara. Ada hubungan antara setiap individu dalam menciptakan kesesuaian dan keharmonisan. Tujuan spesifik dari penelitian ini adalah sebagai berikut. (1) Untuk menganalisis pertimbangan pentingnya Pendidikan Dalam Keluarga berbasis etika Buddha, (2) memahami, menganalisis, dan mendeskripsikan Pendidikan Dalam Keluarga berbasis etika Buddha, dan (3) memahami, menganalisis, dan mendeskripsikan manfaat pendidikan dalam keluarga berbasis etika Buddha. 
Secara teori bahwa kajian dalam artikel ini adalah untuk memberikan tinjauan umum atau wacana akademik berdasarkan nilai-nilai yang terdiri dari teks-teks tulisan suci Tipitaka/Tripitaka, terutama yang berkaitan dengan pendidikan, etika dan kehidupan hittasukkhaya yang diangkat dalam konteks saat ini. Dengan demikian, diharapkan dapat digunakan sebagai referensi dalam pengembangan pengetahuan bagi peneliti lain. Hasil penelitian ini dapat menambah harta kekayaan intelektual penelitian berdasarkan teks tulisan berdasarkan Kitab suci Tipitaka/Tripitaka yang selama ini kurang mendapat perhatian di Indonesia. Hal itu juga dapat digunakan sebagai referensi untuk penelitian lebih lanjut.

Secara praktis hasil dari penelitian pendidikan dalam keluarga berbasis etika Buddha dapat menjadi dasar untuk bertindak, terutama bagi umat Buddha sebagai bagian integral dari masyarakat dalam kehidupan sehari-hari. Hasil penelitian dapat digunakan sebagai panduan dalam kehidupan keluarga, khususnya yang terkait dengan pendidikan pola kehidupan berdasarkan ajaran Buddha. Melalui pemahaman yang baik dan benar tentang pentingnya Pendidikan dalam keluargaberbasis etika Buddha, umat Buddha khususnya dan masyarakat Indonesia pada umumnya dapat menciptakan kehidupan sosial yang bahagia dan sejahtera. Bagi pembaca, penelitian ini dapat digunakan sebagai panduan untuk memahami nilai-nilai ajaran Buddha terkait dengan pendidikan, etika. Lebih luas diharapkan bahwa hasil penelitian ini dapat digunakan sebagai panduan bagi pemimpin dalam pembinaan kepada umat Buddha secara umum, sekaligus arah dan tujuan umat Buddha dalam mengatur kehidupan hittasukkhaya serta dalam melakukan kegiatan di bidang sosialkemasyarakatan berdasarkan pada ajaran Buddha.

\section{Metodologi}

Penelitian pendidikan dalam keluarga Berbasis Etika Buddha ini adalah penelitian kualitatif interpretatif. Rancangan penelitian ini adalah untuk mengidentifikasi teks-teks dari Kitab Suci Tipitaka dan komentar-komentar lain yang sesuai dan terkait dengan pokok bahasan sesuai dengan judul penelitian. Dengan data-data yang terkumpul kemudian dilanjutkan dengan mengkompilasi sesuai dengan bagian. Teks-teks dari Kitab Suci Tipitaka sebagai sumber 
data utama. Sumber data sekunder (pendukung) termasuk bukubuku tentang etika, buku-buku tentang Pokok-pokok Agama Dasar Buddha, Buddha Sejarah Agama, Kemasyarakatan dalam Agama Buddha, dan lainnya yang terkait dengan konten penelitian. Selain itu, pengumpulan data primer dilakukan melalui wawancara dengan para ahli dalam teks-teks agama Buddha. Selanjutnya dilakukan proses analisis data dilakukan dengan reduksi, perbandingan, dan penarikan kesimpulan. Teori - teori utama digunakan untuk menganalisis dan menyelesaikan masalah, yaitu, teori strukturalfungsional, teori hermeneutic, dan teori paticcasamuppada.

Pertama, teori struktural-fungsional untuk memecahkan dan mencari tahu perubahan apa yang terjadi dan dinamika yang terjadi dalam struktur sosial masyarakat/fenomena sosial. Teori fungsionalisme struktural adalah salah satu pengertian atau perspektif dalam sosiologi memandang masyarakat sebagai suatu sistem yang terdiri dari bagian-bagian yang saling berhubungan satu sama lain. Dengan menggunakan teori Struktural-fungsional yang merupakan salah satu teori Sosiologi yang dikemukakan oleh ahli sosiologi Amerika, Talcott Parsons pada sekitar tahun 1950, adalah memberikan gambaran atau abstraksi yang sistematis mengenai kebutuhan fungsional sosial tertentu, bahwa setiap masyarakat harus memelihara dan menjaga agar kehidupan sosial dapat berjalan stabil. Dalam bukunya The Social System, Parson memaparkan teori mengenai struktur fungsional yang bertujuan untuk membuat persatuan pada keseluruhan sistem sosial.

Pokok pikiran Parsons tentang konsep AGIL merupakan pengembangan teori fungsionalisme structural dengan mengemukakan empat prasyarat mutlak yang harus dipenuhi setiap masyarakat, kelompok atau organisasi. Keempat persyaratan fungsional tersebut adalah sebagai berikut: a). Adaptasi (Adaptation), yakni supaya masyarakat dapat bertahan mereka harus mampu menyesuaikan diri dengan lingkungan dan mengubah lingkungan agar dapat sesuai dengan masyarakat. Adaptasi menunjuk pada keharusan bagi sistem-sistem social untuk menghadapi lingkungannya; b). Tujuan (Goal), yakni merupakan sebuah sistem harus mampu menentukan tujuan dan berusaha untuk mencapai tujuan yang telah dirumuskan bersama para anggota dalam sistem 
social; c). Integrasi (Integration), yakni masyarakat harus mengatur hubungan diantara komponen-komponennya agar dapat berfungsi secara maksimal. Sosialisasi mempunyai kekuatan integratif yang sangat tinggi dalam mempertahankan kontrol sosial dan keutuhan keluarga. Integrasi menunjuk pada persyaratan untuk suatu tingkat solidaritas minimal sehingga para anggotanya akan bersedia untuk bekerja sama dan menghindari konflik yang merusakkan; dan d). Latensy atau pemilihan pola-pola yang sudah ada (pattern maintance), yakni bahwa setiap masyarakat memiliki kebutuhan mempertahankan nilai-nilai dasar serta norma-norma yang dianut bersama oleh para anggota dalam masyarakat.

Selain itu bahwa, satu bagian tertentu tidak dapat berfungsi tanpa hubungan dengan bagian lainnya. Jika perubahan terjadi dalam suatu sistem, itu akan terjadi ketidakseimbangan dan perubahan dalam sistem lain. Dalam sistem kehidupan sosial terpadu berdasarkan kesepakatan anggotanya, nilai-nilai sosial tertentu memiliki kemampuan untuk mengatasi perbedaan yang terjadi. Sistem dalam kehidupan perumah tangga bahwa pendidikan dalam keluarga dipandang sebagai sistem yang secara fungsional terintegrasi ke dalam keseimbangan. Ini berarti bahwa keluarga adalah kumpulan dari sistem sosial individu yang terkait dengan saling ketergantungan lain. Asumsi dasar teori fungsionalisme adalah bahwa semua elemen masing-masing individu dalam keluarga harus berfungsi.

Kedua, teori hermeneutik digunakan untuk mendapatkan interpretasi yang benar dari teks yang dimaksud sesuai dengan tujuan penelitian. Istilah hermeneutika secara etimologis berasal dari kata kerja Yunani Kuno yaitu, hermeneuein berarti menafsirkan atau memprediksi. Kata hermenia berasal dari kata benda yang diterjemahkan penafsiran atau interpretasi (prediksi atau interpretasi) (Sumaryono, 1999: 23). Menurut Peirce (2012), semiotik memungkinkan seseorang untuk berpikir tentang tandatanda, terhubung dengan yang lain, dan memberi makna pada apa yang ditampilkan di alam semesta. Tanda-tanda yang berhubungan dengan benda yang menyerupai itu serta memiliki hubungan sebab akibat. Tugas semiotik adalah menemukan koherensi dan menyaring hal-hal penting. Peirce (2012), berharap bahwa teori umum dapat 
diterapkan pada semua jenis tanda. Untuk mencapai tujuan ini, ia membutuhkan konsep-konsep baru. Untuk melengkapi konsepnya, ia menciptakan kata-kata baru ciptaan sendiri (Kaelan, 2009: 166).

Ketiga, teori paticcasamuppada (hubungan sebab akibat). Dalam Nidanasamyutta (khotbah berkelompok tentang sebab akibat) Buddha berpegang pada prinsip ini sebagai alternatif dari ekstrem-ekstrem penjelmaan dan tanpa penjelmaan. Sebab akibat yang saling bergantungan menyediakan kunci bagi pemahaman tentang munculnya penderitaan serta kesenangan dan kesakitan. Sekali lagi untuk memotong berbagai kontradiksi filosofis yang diadopsi oleh para pemikir pada masa Buddha. Formula dua belas faktor dari sebab akibat yang saling bergantungan merupakan ungkapan yang paling umum dari doktrin ini.

Dalam Upanisa Sutta (12:23) yang singkat, tetapi tajam, ditunjukkan bahwa prinsip kondisionalitas yang sama yang mendasari pergerakan penderitaan (samsara) juga memberikan dukungan kuat bagi jalan menuju kebebasan. Tiap-tiap tahap dari sang jalan muncul dengan pendahulunya sebagai kondisi atau penyebab langsung di sepanjang jalan dari tindakan awal keyakinan hingga pengetahuan akhir pembebasan. Prinsip ini kadang-kadang disebut juga "sebab akibat yang saling bergantungan yang transenden". Perputaran ini digerakkan oleh keinginan dan keinginan dipelihara oleh kebodohan. Untuk menghentikan gerakan maju dari rangkaian ini, kebodohan harus diganti dengan pengetahuan. Dengan lenyapnya kebodohan semua faktor yang mengalir darinya keinginan, kemelekatan, dan aktivitas kamma - menjadi berhenti, mengakhiri lingkaran kelahiran kembali dengan semua penderitaan yang menyertainya. Dalam hubungannya dengan Pendidikan dalam keluarga Berbasis Etika Buddha, teori paticcasamuppada sangat tepat digunakan untuk membedah atau menganalisis hal tersebut.

Dalam pengertian yang lebih sempit bahwa pendidikan dalam keluarga berbasis etika Buddha adalah mempelajari motif, tujuan, dan cara yang digunakan oleh setiap individu untuk menciptakan kehidupan yang harmonis. Sebagai suatu teori disiplin ilmu yang mempelajari beberapa sebab, yaitu adanya ketergantungan antara satu dan yang lainnya, paticcasamuppada digunakan dalam 
menganalisis permasalahan-permasalahan dimaksud. Terdapat keterkaitan semua aktivitas dan motif manusia dalam semua aspek dalam membangun kehidupan keluarga yang sejahtera dan bahagia. Semua aktivitas yang dilakukan oleh manusia yang bervariasi pada akhirnya sesuai ajaran Buddha harus ditujukan pada perkembangan moral dan perkembangan batin. Oleh karena itu, ditekankan pentingnya etika moral dan perkembangan karakter individu dalam pendidikan kehidupan hittasukkhaya.

Walshe (1987,1995) dalam Sutta Pitaka, Digha Nikaya, Mahanidana Sutta, mengutarakan bahwa ajaran sebab musabab yang saling bergantungan ini sangat dalam (gambhiro) dan muncul sangat dalam (gambhirovabhaso). Karena tidak memahami dan tidak menembus ajaran ini, generasi ini telah menjadi seperti rumput kasar, tidak mampu melampaui alam sengsara, kejatuhan, dan terperangkap dalam kelahiran dan kematian. Oleh karena itu, dalam mempelajari paticcasamuppada harus dipahami secara benar.

\section{Hasil dan Pembahasan}

\section{Mengapa Pendidikan Dalam Keluarga Berbasis Etika Buddha?}

Dalam ilmu pendidikan dan organisasi, dikenal istilah "Survival of The Fittest". Istilah ini mengandung pengertian bahwa keberlangsungan hidup satu entitas (individu atau organisasi) adalah yang berhasil menyelaraskan kepentingan di dalam (internal) dan di luar (eksternal). Kepentingan internal dan eksternal sendiri tidaklah tetap atau statis. Keduanya terus berubah dari waktu ke waktu. Oleh karenanya, untuk bisa bertahan atau menjaga kelangsungan hidupnya, suatu entitas harus terus berubah, harus terus menyesuaikan.

Dalam perspektive sosiologinya, Parson memandang masyarakat sebagai suatu sistem yang terdiri dari bagian-bagian yang saling berhubungan satu sama lain. Oleh karena itu, bahwa hidup berkeluarga dalam hal ini adalah kumpulan masyarakat individu yang membentuk kesatuan dalam kehidupan berkeluarga. Perubahan-perubahan yang terjadi satu dan yang lainnya dalam kehidupan keluarga akan saling memengaruhinya. Parson juga mengungkapkan bahwa satu bagian tidak dapat berfungsi tanpa hubungan dengan bagian lainnya. Jika ada bagian dari individu dalam 
keluarga yang tidak berfungsi maka akan terjadi ketidakseimbangan, bahkan dapat menyebabkan tidak berfungsinya individu yang lain. Oleh karena itu, dalam sistem kehidupan sosial bittasukkhaya terpadu berdasarkan kesepakatan anggotanya, nilai-nilai sosial tertentu memiliki kemampuan untuk mengatasi perbedaan yang terjadi untuk mencapai tujuan yang diharapkan.

Terkait dengan hal tersebut diatas, pada dasarnya diawali dari pendidikan diri individual untuk melaksanakan fungsi struturalnya masing-masing. Sebagaimana Buddha ajarkan bahwa setiap individu dalam usaha untuk menciptakan kemajuan spiritualnya diawali dari pengelolaan dan pengendalian diri terhadap pikiran, ucapan, dan perbuatan dari badan jasmani. Setiap individu dari bagian keluarga sebanyak mungkin melakukan hal-hal yang benar dan menghindari hal-hal yang salah. Alasan melakukan hal-hal yang "benar" adalah yang baik, yang pantas, dan bermanfaat bagi diri sendiri dan juga bermanfaat bagi orang lain, bermanfaat untuk semua pihak. Adapun hal-hal yang salah adalah merugikan diri sendiri dan juga merugika orang lain. Dalam ilmu pendidikan sistem dan pendidikan operasi (dulunya disebut pendidikan produksi), terdapat satu proses yang sangat mendasar berupa sebuah sistem umum. Proses sistem tersebut berbentuk suatu aliran, yaitu masukan (input), proses (transformasi), keluaran (output).

Hasil wawancara dengan seorang tokoh Buddhis Bpk. Jo Prisatana, M. Hum, beliau mengatakan bahwa etika menyangkut sistem etik, dan pencarian happynes. Lima latihan moral yaitu: menghindari membunuh, menghindari mencuri, menghindari berbuat asusila, menghindari berdusta dan menghindari mabukmabukan (Pañcas $\square$ la Buddhis) ini sebagai dasar etika sosial yang dimiliki Buddhisme. Dasar dalam etika sosial dalam Buddhisme memandang bahwa permasalahan mendasar yang menjadi penyebab penyimpangan sosial adalah permasalahan yang diawali dari diri pribadi. Permasalahan pokok diri pribadi yang sangat mendasar adalah bahwa setiap orang membawa bekal masa lalu berupa lobha (keserakahan), dosa (kebencian), dan moha (ketidaktahuan/ kebodohan). Etika berperan untuk menjaga sistem stuktur sosial dalam kehidupan perumah tangga. Hal ini sejalan dengan pemikiran Parsons. Asumsinya bahwa setiap anggota keluarga memiliki fungsi 
masing-masing dan bekerja sesuai dengan fungsinya sebagai sebuah sistem. Setiap anggota keluarga berada dalam sistem sosial yang saling berinteraksi. Etika moral Buddha dibangun dan menempatkan bahwa setiap anggota keluarga memiliki kedudukan yang sama dalam menerapkan etika dalam hubungannya dengan membangun keluarga yang harmonis.

Demikian juga hasil wawancara dengan Bpk. Gimin Edi Susanto, BA. Hons, beliau menjelaskan bahwa kehidupan sejalan dengan berlakunya hukum kamma. Buddha memberikan petunjuk bahwa "Kalyanam va papakam va tassa dayada bhavisanti" yang berarti kebaikan atau kejahatan kita akan menjadi ahli waris. Paritta suci, Brahmaviharapharana (hal.38--39). Mencari keuntungan dengan benar, akan mendapatkan kebahagiaan yang lama. Sebaliknya, bila mencari keuntungan dengan salah, kebahagiaan akan sebentar, bahkan dapat menimbulkan kebangkrutan. Nilai etika moral menjadi pedoman dalam berpenghidupan benar dan akan menentukan hasil yang akan diperoleh di kemudian hari. Jasi etika moral menjadi pegangan dan panduan dalam berpenghidupan benar.

Seorang pengusaha Buddhis yang sukses Bpk. David Hermanjaya (pemilik karoseri New Armada, dll) bertempat tinggal di Magelang Jawa Tengah, beliau menyatakan bahwa kesuksesan dapat diperoleh oleh siapapun termasuk umat Buddha asalkan dibangun dengan kejujuran. Beliau mengungkapkan bahwa dalam ajaran Buddha kejujuran adalah modal penting, ditambah lagi dengan semangat dan ulet. Kalau ingin sukses tidak ada sesuatu yang instan, semua mengalami proses. Dalam mencapai tujuan, kegagalan adalah wajar, dan terus diperjuangkan dengan keuletan, semangat, pantang menyerah. Kejujuran adalah salah satu etika atau ajaran Buddha yang harus diterapkan oleh siapa pun, baik pengusaha, karyawan, guru, siswa dan sebagainya. Etika kejujuran menjadi pedoman dalam berperilaku sehari-hari.

Dalam membangun pendidikan dalam keluarga maka memiliki pengetahuan dhamma (pariyatti dhamma) sebagai tahapan awal membangun keyakinan sebagai dasar acuan pendidikan diri pribadi. Selanjutnya dengan memiliki pengetahuan yang baik 
akan mendukung bagaimana cara praktik dhamma secara benar (patipatti dhamma). Dengan keyakinan (saddha) akan mendukung setiap individu untuk melakukan pelatihan diri dalam membangun berpikir yang baik dan selaras, membangun ucapan yang baik dan benar serta membangut tindakan atau tingkah laku yang baik dan benar untuk menciptakan dan meraih kedamaian dan kebahagiaan dalam hidup hittasukkhaya. Dalam proses membangun pendidikan individu perlu proses tahapan sehingga mendapatkan hasil melalui implementasi melalui proses bhavana (pativedha dhamma). Oleh karena itu, bahwa pendidikan yang dikembangkan menjadi fondasi yang kuat dan berkelanjutan yang akan menghasilkan kedamaian, kebahagiaan sebagai tujuan hidup hittasukkhaya. Pendidikan menjadi sangat penting dalam individu dan menjadi sebuah keniscayaan dalam kehidupan hittasukkhaya.

\section{Bagaimana Pendidikan Dalam Keluarga Berbasis Etika Buddha?}

Etika Buddha dalam Tipitaka/Tripitaka dapat ditemukan dalam aspek pembentukan pribadi, merawat orang lain. Dalam Dhammapada, Danda Vagga.131, Buddha menyatakan: "Seseorang yang mencari kebahagiaan dengan menyakiti orang lain yang juga mendambakan kebahagiaan, maka orang itu tidak akan mendapatkan kebahagiaan setelah kematiannya. Orang yang mencari kebahagiaan dengan tidak menyakiti orang lain yang juga mendambakan kebahagiaan, maka mereka akan mendapatkan kebahagiaan setelah mati". Dalam situasi perubahan dan kecemasan yang tidak menentu, kepedulian terhadap orang lain diperlukan untuk menciptakan kehidupan yang harmonis.

Pada umumnya ada tiga sistem norma moral yang digunakan sebagai patokan, yaitu norma berdasarkan kepercayaan pada kewajiban absolut (deontologis), norma berdasarkan tujuan tindakan (teleologis), atau norma berdasarkan hubungan dengan orang lain (relasional). Moral atau etika Buddha menyangkut kebaikan-kebaikan. Etika juga tentang kebaikan, yaitu kemampuan untuk menilai apa yang baik dan apa yang buruk. Dalam agama, etika adalah faktor pendorong yang mendorong dan mendasari gagasan dan perbuatan. Ajaran Buddha sangat menekankan moralitas dan etika dalam kehidupan hittasukkhaya maupun dalam pengembangan spiritual. Perkembangan moral adalah manifestasi 
dari perlunya pengembangan diri dalam proses kehidupan manusia. Tidak berbuat jahat (sabbapapassaakaranam), tambahlah kebajikan (kusalaupasampada) dan memurnikan hati dan pikiranmu (sacittapariyodapanam). "Ini adalah inti dari ajaran Buddha yang dibabarkan kepada siswa-Nya sebanyak 1250 orang bhikkhu..

Bodhisattva (calon Buddha) memiliki solidaritas dan kepedulian serta tekad penuh kasih untuk membantu seluruh makhluk untuk memimpin pencerahan. Tekad penuh kasih untuk membantu semua makhluk adalah yang mendasari motivasi altruistik dalam membantu perilaku di kalangan umat Buddha. Motivasi altruistik didasarkan pada penghargaan atas kesatuan manusia dengan lingkungan dan alam semesta, termasuk empati terhadap penderitaan makhluk hidup.

Dalam menciptakan kehidupan dalam kekuargaa yang bahagia dan sejahtera, satu diantaranya adalah terpenuhinya sarana pada bidang ekonomi. Dalam Ariya Atthangika Magga, Cattari Ariya Saccani, Dhammacakkhapavatthana Sutta dapat ditemukan dalam aspek mata pencaharian yang tepat dan menghindari mata pencaharian yang salah. Penghidupan benar (samma ajiva) dalam Sutta Pitaka, Anguttara Nikâya III, 208, Sang Buddha menyatakan kepada siswa-siswanya, bahwa ada lima jenis perdagangan salah (micchâvanijja) yang harus dihindari umat Buddha, yaitu perdagangan senjata, perdagangan makhluk hidup, perdagangan daging, perdagangan racun, dan perdagangan alkohol. Dasar menghindari lima jenis perdagangan yang salah adalah dalam upaya pengembangan spiritual menuju terciptanya kebahagiaan batin. Seseorang akan dapat mengembangkan sikap peduli dengan orang lain jika seseorang telah mengembangkan sikap yang mulia.

Untuk dapat terlaksananya penghidupan benar bagi perumah tangga, haruslah benar-benar memahami jalan mulia berunsur delapan. Buddha mengajarkan dhamma mengawali dengan dasar pengertian benar (samma ditthi) dan pikiran benar (samma sankhapa). Ini menjadi landasan untuk dapat terwujudnya halhal yang lainnya. Oleh karena itu, bahwa pengertian benar dan pikiran benar menjadi landasan untuk dapat terciptanya ucapan benar, pikiran benar maupun penghidupan benar. Ini merupakan 
hubungan yang saling bergantungan satu dengan yang lainnya.

Empat kondisi pikiran mulia telah diajarkan oleh Buddha, yaitu cinta kasih (metta), belas kasihan (karuna), simpati (mudita) dan keseimbangan batin (upekkha). Dengan memiliki empat kondisi mental ini, seseorang dapat dikatakan berdiam dalam kondisi yang luhur dan juga dikenal sebagai brahma-vihara. Memiliki mental yang sempurna, adalah cara bertindak dan menjadi benar dan ideal untuk semua makhluk hidup (sattesu samma patipatti). Dengan memiliki empat kondisi mental dimaksud adalah sekaligus menjawab semua situasi yang muncul dan panduan dalam menghadapi kehidupan sosial di masyarakat. Cinta kasih, kasih sayang, simpati dan memiliki keseimbangan batin adalah cara untuk menciptakan kondisi damai dalam konflik social kemasyarakatan. Selain itu, ia juga menghancurkan hambatan-hambatan yang terjadi dalam membangun hubungan social kemasyarakatan. Melalui pengembangan batin yang tinggi maka akan memudahkan dalam membangun komunitas yang harmonis dalam kehidupan hittasukkhaya. Dengan Cinta kasih dan kasih saying akan membangkitkan kemurahan hati, menghidupkan kembali kebahagiaan. dan mendorong kepedulian terhadap setiap individu dalam keluarga sebagai sesama dalam hubungan persaudaraan yang bahagia.

Setiap individu dalam usaha untuk menciptakan keharmonisan dalam kehidupan keluarga dan sekaligus kemajuan spiritualnya diawali dari pengelolaan dan pengendalian diri terhadap pikiran, ucapan, dan perbuatan dari badan jasmani. Dalam hal pengelolaan diri individu, maka peran moral atau etika menjadi sangat penting dan menjadi landasan dalam semua perilaku setiap individu sebagai bagian dari keluarga. Oleh karena itu, pendidikan yang dibangun dan dikembangkan adalah berlandaskan moral/etika sebagaimana Buddha ajarkan dalam menciptakan kehidupan keluarga yang harmonis dan sejahtera. Penekanan pada pentingnya etika Buddha dalam kehidupan hittasukkhaya berdasarkan pada hasil penelitian dan diskusi dapat dirangkum bahwa etika Buddha bertujuan untuk menciptakan kehidupan rumah tangga yang bahagia dan sejahtera. Perlu mengatur pendidikan sistem keluarga dengan baik dan benar sehingga penghuni rumah bebas dari ketidakhamonisan. 
Apa Manfaat Pendidikan Dalam Keluarga Berbasis Etika Buddha?

Manfaat Pendidikan dalam keluarga Berbasis Etika Buddha adalah membantu untuk setiap individu dalam membuat strategi yang lebih baik dengan menggunakan pendekatan yang lebih sistematis, logis, rasional pada pilihan strategis. Hal ini terkait dengan pengembangan pembangunan kehidupan keluarga dalam menciptakan keluarga bahagia dan sejahtera (bittha sukkhaya). Pendidikan Buddha perlu dikembangkan oleh setian individu bagian dari keluarga dalam menghadapi situasi dan kondisi saat ini. Hal ini terkait dengan pembangunan karakter manusia dalam kesiapannya menghadapi segala macam yang terjadi dalam kehidupan masyarakat.

Etika berlandaskan ajaran Buddha adalah perwujudan dari kebutuhan pengembangan pribadi setiap individu manusia yang selalu berproses. Buddha menekankan untuk menegakkan moralitas atau mempraktikkan sila, hidup dalam kondisi moral. "Jadilah pulau untuk dirimu sendiri." Ini adalah moralitas independen atau hidup adalah milik kita sendiri yang secara kritis dapat memutuskan mana yang baik dan mana yang benar, yang dapat kita lakukan melalui kesadaran yang terkandung di dalam diri kita. Karena itu, etika memiliki peran dalam menciptakan harmoni dalam tatanan kehidupan manusia bersama. Lima disiplin moral menjadi tolok ukur tindakan bagi rumah tangga dalam membangun keharmonisan keluarga terkait dengan kehidupan masyarakat, bangsa, dan negara. Konsistensi implementasi dari lima disiplin moral adalah penting, karena setiap kemajuan di negara dan negara dimulai dengan kehidupan setiap rumah tangga.

\section{Kesimpulan}

Berdasarkan analisis penelitian pendidikan berbasis etika Buddha dalam kehidupan hittasukkhaya dapat ditarik beberapa kesimpulan sebagai berikut: 1) Pendidikan berbasis etika Buddha menjadi penting dalam kehidupan hittasukkhaya digunakan sebagai arah atau pedoman dalam menciptakan kehidupan hittasukkhaya. Pengelolaan dan pengendalian diri terhadap pikiran, ucapan, dan perbuatan dari badan jasmani menjadi dasar bagi setiap individu sebagai bagian dari keluarga sebanyak mungkin melakukan hal- 
hal yang benar dan menghindari hal-hal yang salah. 2) Sebagai bagian dari kehidupan dalam keluarga, peran setiap individu sangat penting dalam menciptakan keharmonisan dan sekaligus kemajuan spiritualnya yang diawali dari pengelolaan dan pengendalian diri terhadap pikiran, ucapan, dan perbuatan dari badan jasmani. Dalam hal pengelolaan individu, maka peran moral atau etika menjadi sangat penting dan menjadi landasan dalam semua perilaku setiap individu sebagai bagian dari keluarga. Oleh karena itu, pendidikan yang dibangun dan dikembangkan adalah berlandaskan moral/ etika sebagaimana Buddha ajarkan dalam menciptakan kehidupan keluarga yang harmonis dan sejahtera. 3) Manfaat pendidikan dalam keluarga Berbasis Etika Buddha adalah membantu untuk setiap individu dalam membuat strategi yang lebih baik dengan menggunakan pendekatan yang lebih sistematis, logis, rasional pada pilihan strategis. Hal ini terkait dengan pengembangan pembangunan kehidupan hittasukkhaya dalam menciptakan keluarga bahagia dan sejahtera (bittha sukkhaya).

\section{Daftar Pustaka}

Aggabalo, Bhikkhu. 2007. Dhammapada Atthakatha. Jakarta: Perpustakaan Narada.

Bachtiar. 2006. Sosiologi Klasik, Dari Comte hingga Parsons. Bandung: PT Remaja Rosdakarya.

Beilharz, Peter. 2002. Ed. Teori-Teori Sosial. (Sosial Theory: A Guide to Central Thinkers). Diterjemahkan oleh: Sigit Jatmiko. Cetakan I. Yogyakarta. Pustaka Pelajar.

Boddhi. Bhikkhu. 1995. The Middle Length Discourse of the Buddha, A Translation of the Majjhima Nikaya.. Boston: Wisdom Publications.

- 2013. Tipitaka Tematik Sabda Buddha dalam Kitab Suci Pali. Jakarta: Ehipassiko Foundation.

Bleicher, Josef. 2013. Hermeneutika Kontemporer (Hermeneutika sebagai Metode, Filsafat dan Kritik. Yogyakarta: Fajar Pustaka.

Dédé Oetomo. 2013. Penelitian Kualitatif: Aliran \& Tema. Metode Penelitian Sosial: Berbagai Alternatif Pendekatan (Editor oleh Bagong Suyanto \& Sutinah). Jakarta: Kencana 
Dhammadhiro, Bhikkhu. 2005. Paritta Suci: Kumpulan Pali Wacana untuk Upacara dan Puja. Jakarta: Sangha Theravada Indonesia.

Dhammananda, Kirinde Sri. 2005. Keyakinan Umat Buddha. Jakarta:Yayasan Penerbit Karaniya

Dhiltey, Wilhem. 1962. Pattern and Meaning in Historiy, New York: Harper \& Row.

Dwi Susilo, Rachmad K. 2008. 20 Tokoh Sosiologi Modern. Yogyakarta: Ar-Ruzz Media.

Gadamer, Hans-Georg. 1977. Philosophical Hermeneutics, trans dan ed. David E. Linge, Berkeley: The University of California Press

George Ritzer \& Douglas J. Goodman. 2008. Teori sosiologi. Yogyakarta: Kreasi Wacana.

Horner, I.B. 1975. The Minor Anthologies of the Pali Canon Part III: Chronicle of Buddhas (Buddhavamsa) and Basket of Conduct (Cariyapitaka). London: The Pali Text Society.

Iin Suwarni, 2016. Pembelajaran Kontekstual pada Pendidikan agama Buddha. Jurnal Vijjacariya, Volume 3 Nomor 1, hal 129-139.

Indiwan, Seto Wahyu Wibowo. 2011. Semiotika Komunikasi. Jakarta; Mitra Wacana Media. 13-25.

Jataka, sumber https://samaggi-phala.or.id/naskah-dhamma/isi-kitabjataka.

Jutanago (ed.). 1985. Kitab Suci Dhammapada. Jakarta: Yayasan Dhammadipa Arama.

Lay. U. Ko. 2000. Guide To Tipitaka (Panduan Tipitaka Kitab Suci Agama Buddha.) alih bahasa Lanny Anggawati dan Wena Cintiawati, Klaten: Vihara Bodhiwamsa.

Maurice, Walshe. 1995. Kotbah-kotbah Panjang Sang Buddha Digha Nikaya. Jakarta: Dhamma Citta Press.

Moleong, Lexy. J. 2012. Metodologi Penelitian Kualitatif (Edisi Revisi). Bandung: Remaja Rosdakarya.

Mulyana, 2014. Konstruksi Kearifan Lokal dan Etika Buddha Dalam perspektif Kepemimpinan Modern. Jurnal Pelita Dharma. Edisi I, hal. 75-86.

Narada. 1988. The Buddha and His Teaching. Kuala Lumpur: Publication 
of the Buddhat Missionary Society.

Nyanaponika Thera dan Bodhi Bhikkhu. 2002. Petikan Anguttara Nikaya, 1, 2, 3, dst. (Translator Dra. Lanny Anggawati \& Dra. Wenna Cintiawati). Klaten: Vihara Bodhivamsa Wisma Dhammaguna.

Nyanatiloka. 1970. Buddhat Dictionary: Manual of Buddhat Terms and Doctrines. Singapore: Singapore Buddhat Meditation Centre.

Palmer, Richard E. 2005. Hermeneutika: Teori Baru Mengenai Interpretasi. Di- Indonesiakan oleh Musnur Hery \& Damanhuri Muhammed, dari judul asli Hermeneutics: Interpretation Theory in Schleiermacher, Dilthey, Heidegger, and Gadamer, Cet. Ke-2, Yogyakarta: Pustaka Pelajar.

Peter, Harvey. 2000. An Introduction to Buddhat Ethics. Cambridge: University Press.

Priastana, Jo. 2000. Buddha Dharma Kontekstual. Jakarta: Yayasan Yasodhara Putri.

Rashid, Teja. 1997. Sila dan Vinaya, Jakarta: Penerbit Buddha Bodhi.

Riceour, Paul. 2014. Teori Interpretasi Membelah Makna dalam Anatomo Teks. Yogyakarta: IRCiSod.

Sapardi .2018. Peran Etika Buddha Daam Menjaga Sistem Kehidupan Perumah Tangga Dalam kajian Fungsionalisme Struktural. Jurnal Vijjacariya. Vol.5 No. 2 Edisi Desember 2018. Hal 129-139.

Schumacher. E.F. 'Small is Beautiful". (Ekonomi Buddha oleh Phra Brahmauntukbhorn (P. A. Payutto) diterjemahkan oleh J.B. Dhammavijaya).

Schleiermacher F.D.E. 1977. Hermeneutics: The Handwritten Manuscripts, ed.

Sugiyono. 2007. Memahami Penelitian Kualitatif. Bandung: Penerbit Alfabeta.

Walse. Maurice. 2009. Digha Nikaya, The Long Discourses of the Buddha A Translation of the Digha Nikaya (Khotbah-khotbah Panjang Sang Buddha Digha Nikaya). Jakarta: DhammaCitta Press.

Wowor, Cornelis. 1997. Pandangan Sosial Agama Buddha. Jakarta: Arya Surya Chandra. 